\title{
PARA MULHERES MARGINAIS, EPISTEMOLOGIAS MARGINAIS: RELIGIÃO, INTERCULTURALIDADE E DESCOLONIZAÇÃO
}

\author{
Cristina Borges*
}

\begin{abstract}
RESUMO
O artigo trata da articulação entre religião, epistemologia descolonial e gênero no bojo das transformações do mundo contemporâneo. Para tanto, aborda conceitos como colonialidade, diferença colonial e interculturalidade. $O$ último conceito, enquanto processo descoIonial. A interculturalidade é demonstrada por meio do trabalho de uma sacerdotisa das religiões afro-brasileiras que em conexão com a ancestralidade dialoga com conhecimentos atuais, aplicando-os na resolução de problemas daqueles que buscam seus serviços. Subsidiam este trabalho autores do pensamento descolonial a saber: Walter Mignolo, Catherine Walsh e a feminista descolonial Maria Lugones. Palavras-chave: Religiões afro-brasileiras. Colonialidade. Descolonização. Gênero. Exu.
\end{abstract}

\section{PARA LAS MUJERES MARGINALES, EPISTEMOLOGÍAS MARGINALES: RELIGIÓN, INTERCULTURALIDAD Y DESCOLONIZACIÓN}

\begin{abstract}
RESUMEN
El artículo trata de la articulación entre religión, epistemologia descolonial y género en selo de las transformaciones del mundo contemporáneo. Por lo tanto aborda conceptos como colonialidad, diferencia colonial e interculturalidad. Este último concepto como processo descolonial. La interculturalidad es demonstrada a través de una sacerdotisa das religiones afrobrasileñas, que en conexión con la ancestralidade, dialoga con conocimientos actuales, aplicandolos en la resolución de problemas de aquellos que buscan sus servicios. Subsidian ese trabajo autores del pensamiento descolonial a saber: Walter Mignolo, Catherine Walsh y la feminista descolonial Maria Lugones.

Palabras clave: Religiones afrobrasileñas. Colonialidad. Descolonización. Género. Exu.
\end{abstract}

* Doutora em Ciências da Religião. Professora do Departamento de Filosofia e pesquisadora do Núcleo de Estudos Afro-Brasileiros da Universidade Estadual de Montes Claros (UNIMONTES). Pesquisadora da Escola Internacional de Filosofia Intercultural. 


\title{
FOR MARGINAL WOMEN, MARGINAL EPISTEMOLOGIES: RELIGION, INTERCULTURALITY AND DECOLONIZATION
}

\begin{abstract}
The article deals with the articulation between religions, decolonial epistemology and gender in the midst of the transformations of the contemporary world. To do this, he addresses concepts such as coloniality, colonial difference and interculturality. This last concept, as a decolonial process. Interculturality is demonstrated through a priestess of Afro-Brazilian religions who, in connection with ancestrality, dialogue with current knowledge, applying them in solving problems of those who seek their services. This work is subsidized by authors of decolonial thought, namely Walter Mignolo, Catherine Walsh and the decolonial feminist Maria Lugones.

Keywords: Afro-Brazilian religions. Coloniality. Decolonization. Gender. Exu.
\end{abstract}

Para

Valdeci Gonçalves Pereira Andrade, Mãe Dogi.

A contemporaneidade tem suscitado reflexões que demonstram a preocupação, na atualidade, sobre o convívio entre diferentes, desde a diversidade cultural e racial até questões como sexualidade, lugar das religiões e validade das epistemologias ocidentais na leitura acerca da realidade e do gênero.

Neste ensaio, nos arriscamos a articular religião, gênero e epistemologia enquanto uma das tensões próprias do mundo pós-moderno. Esse moderno, marcado pelo fluxo da diversidade e da diferença e, pela resistência às mudanças. São temas que nos remetem a questões atuais como o pluralismo epistemológico, o lugar das religiões na produção de conhecimentos e as mulheres como agentes da fé. Também suscitam reflexões que dizem respeito ao problema do conhecimento, ao fenômeno religioso e ao machismo.

Discussões em torno dessas temáticas irrompem como desafio frente ao sectarismo próprio e característico dos dias atuais. Sectarismo que se põe não apenas como apego exagerado a um ponto de vista, mas, sobre- 
tudo, porque é expresso em discursos e ações de combate às diferenças, a sistemas simbólicos marginais como as religiões e, ao direito das mulheres. Em especial, nos referimos à articulação entre religião, epistemologia do sul'/epistemologias marginais e mulheres sacerdotisas detentoras de conhecimentos que, comumente, são atribuídos aos homens.

Partimos do seguinte pressuposto: o sacerdócio feminino nas religiões de matriz africana pode ser uma ação descolonizadora à medida que coloca a mulher enquanto especialista dos conhecimentos dos antepassados e, predisposta a um sacerdócio intercultural. Prática que, acreditamos, desafia concepções teológicas de tradicionais universos religiosos hegemônicos e epistemologias ocidentais. Práticas que somente vêm à baila mediante epistemologias marginais.

O filósofo Boaventura Santos (2009) apresenta a seguinte definição de epistemologia do Sul: aprender que existe o Sul; aprender a ir para o Sul; aprender a partir do Sul e com o Sul. Para Boaventura Santos (2009, p. 9), epistemologia é:

Toda noção ou ideia, reflectida ou não, sobre condições do que conta como conhecimento válido. É por via do conhecimento válido que uma dada experiência social se torna intencional e inteligível. Não há, pois, conhecimentos sem práticas e actores sociais. E como umas e outros não existem senão no interior de relações sócias, diferentes tipos de relações sociais podem dar origem a diferentes epistemologias. (...). No seu sentido mais amplo as relações sociais são sempre culturais (intra-culturais ou inter-culturais) e políticas (representam distribuições desiguais de poder). Assim sendo, qualquer conhecimento válido é sempre contextual, tanto em termos de diferença cultural como em termos de diferença política. Para além de certos patamares da diferença cultural e política, as experiências sociais são construídas por vários conhecimentos, cada um com os seus critérios de validade, ou seja, são constituídas por conhecimentos rivais.

Como ele, pensadores da atualidade consideram como epistemologia "toda noção ou ideia, reflectida ou não, sobre condições do que conta como conhecimento válido", bem como, a constatação de que

Epistemologia do Sul neste texto se refere às epistemologias marginais como o pensamento descolonial e o pensamento intercultural. 
todo conhecimento válido é contextual. O filósofo usa a metáfora do Sul para designar a diversidade epistemológica, isto é, a existência de diversas epistemologias e seus contextos. A respeito disso, questões se colocam: do que tratam tais epistemologias? Qual a sua validade para reflexões sobre o mundo contemporâneo?

O fato de serem contextuais nos fornece pistas para respostas às tais questões. São conclusões e métodos críticos, advindos de espaços geográficos onde intelectuais nativos se indignam com todas as formas de imperialismo, entre eles o epistemológico. Por serem contextuais, são marginais porque seus intelectuais - a maioria proveniente das regiões que foram colonizadas a partir do século XVI -, experimentam a opressão imperialista ao constatarem sua própria exclusão nas academias quando tentam fazer frente a tal domínio, demonstrando sua inautenticidade. São epistemologias que geram rupturas com a episteme ocidental sem, contudo, negá-la. Promovem um giro epistemológico, pois são desobediências epistemológicas ao enunciarem críticas à epistemologia ocidental, por meio do desvelamento de outras formas de conhecimento não vislumbradas pela ciência, teologia e filosofia ocidentais. Como exemplo, o conhecimento religioso feminino nas religiões de matriz africana.

Em especial, neste ensaio, abordaremos o pensamento descolonial e sua extensão ao feminismo latino-americano. O último tem-se debruçado sobre ações descolonizadoras de mulheres nas religiões afro-brasileiras como Umbanda e Candomblé. Religiões onde mulheres são agentes da fé.

Entender el pasado y hablar el presente é uma máxima do pensamento descolonial e característica marcante das reflexões de Walter Mignolo, intelectual da descolonização que ampliou o conceito de colonialidade ${ }^{2}$ do sociólogo peruano Aníbal Quijano (1992, 2005). De acordo com Francisco Carballo (2014, p. 15-16), o pensamento de Walter Mignolo se constitui de seis pontos fundamentais. ${ }^{3}$ Coerentes com a proposta do texto, apresentaremos os seguintes:

Conceito central do pensamento descolonial.

3 Segundo Francisco Carballo, a trilogia The Darker Side of the Renaissance (O lado mais escuro da Renascença, 1995), Histórias locais/Projetos globais (2003) e The Darker Side of Western Modernity (O lado mais escuro da Modernidade Ocidental, 2011) - escritos de Mignolo - resume ideias, conceitos e posicionamentos descoloniais desse filósofo. 
A "colonialidade" está indissoluvelmente ligada à criação e desenvolvimento do mundo moderno. Em outras palavras: é constitutiva da modernidade e não um de seus produtos derivados. O que queremos dizer com "colonialidade"? Colonialidade é baseada na classificação racial / étnica / sexual / epistêmica dos seres humanos. Essa classificação tem sido a base da lógica imperial e sobreviveu às diferentes encarnações históricas do colonialismo. Deve-se dizer que, Mignolo propôs durante décadas esclarecer os legados coloniais, aqueles que sobrevivem desde o século XVI e ainda influenciam o mundo contemporâneo. ${ }^{4}$

O questionamento fundamental da expansão europeia pelo mundo é que universalizou uma história local (a da Europa) ao mesmo tempo que silenciava ou desvalorizava todas as demais. ${ }^{5}$

A nossa época é uma época de mudança geopolítica. Os países até agora periféricos vão adquirindo um papel de primeiríssima importância. As velhas estrelas do Ocidente, por sua vez, correm o perigo de converterem-se em atores que dividirão com outros a cena internacional. Essa transformação racial e cultural do poder terá consequências de longo alcance. Por princípio de contas, voltamos a um mundo com múltiplos centros de poder político, econômico e científico. É um mundo marcado também pela descentralização estética e religiosa. ${ }^{6}$

Um espectro corre pelo mundo. Política descolonial e disputas ambientais. Ele também discute o léxico filosófico e científico herdado da tradição europeia, o único autorizado a pensar e fazer política durante os três séculos anteriores.?

4 La "colonialidad" esta indisolublement ligada a la creación y el desarrollo del mundo moderno. En otras palavras: es constitutiva de la modernidade y no uno de sus produtos derivados. ¿A qué nos referimos por "colonialidad"? La colonialidad se funda em la clasificación racial/étnica/ sexual/epistémica de los seres humanos. Esta clasificación há sido sustento de la lógica imperial y há sobrevivido a las diferentes encarnaciones históricas del colonialismo. Debe decirse que Mignolo se propuso, desde hace décadas, hacer patentes los legados coloniales, esos que sobreviven desde el Siglo XVI e influen todavia en el mundo contemporâneo.

5 El cuestionamiento de fondo a la expasión europea por el mundo que universalizó una historia local (la suya) al tempo que silenció o devaluó todas as demás.

6 La nuestra es una época de cambio geopolítico. Los países hasta ahora periféricos van adquiriendo un papel de primeirísima importancia. Las viejas estrellas de Occidente, por su lado, corren el peligro de convertirse em actores de reparto en la escena internacional. Esta transformación racial y cultural del poder tendrá consecuencias de enorme calado. Por principio de cuentas volvemos a un mundo con múltiples centros de poder político, económico y científico. Se trata de un mundo marcado, asimismo, por descentramientos estéticos y religiosos.

7 Un espectro recorre el mundo. La política descolonial riñe y ambientales. Discute, también, con el léxico filosófico y científico heredado de la tradición europea, único permitido para pensar y hacer política durante los tres siglos anteriores. 
O conceito de colonialidade tem o pressuposto da raça como fundamento do padrão universal de classificação social básica e de dominação social. A expansão europeia provocou, a partir do século $\mathrm{XVI}$, o movimento de uniformização de ser e de viver de diversas e diferentes sociedades culturais que, dominados pela supremacia técnica dos europeus, assistiram serem minados seus padrões de expressão e de produção do conhecimento. A uniformização europeia é pressuposto basilar na inauguração da Modernidade, narrativa constituída do seguinte conteúdo: o ser europeu é superior a todos os outros seres. Igualmente é superior sua cultura.

Almejando se diferenciarem dos povos dominados, os europeus conceberam a ideia de raça e, sobre essa categoria, instituíram relações sociais que produziram novas identidades e papéis sociais, a saber: negro-escravidão, indígena-servidão, branco-trabalho assalariado. Tais relações de dominação colonial contribuíram para a formação da nova estrutura global de controle do trabalho, que incorporou diversas histórias locais/culturais (regiões e culturas), configurando dessa forma uma intersubjetividade mundial que sustentou e legitimou todas as formas de controle do trabalho em torno do capital. Raça, etnia, classe social e gênero são constructos do novo padrão mundial de poder que se alimenta da exploração, expropriação e violência do negro, indígena, mestiço, pobres e mulheres.

Enquanto centro do capital, a Europa impôs e consolidou seu domínio colonial sobre outras regiões e populações do planeta, incorporando-as a um sistema de proporções planetárias, o Sistema Colonial Moderno. Caracteriza esse sistema, na atualidade, a universalização de uma história local (europeia). Para isso, todas as outras foram silenciadas pelos mecanismos de opressão e repressão europeus. Assim se constituiu a Modernidade como autonarrativa europeia.

Modernidade e Colonialidade são constitutivas. Ou seja, para que os europeus se tornassem a raça dominadora foi preciso, por iniciativa dos mesmos, subjugar pelo colonialismo regiões como a América e África. Isso, mediante a barbárie da escravidão, da servidão, que dizimou vidas, impediu a reprodução de conhecimentos milenares, destruiu padrões próprios de expressão, reprimiu formas de religiosidade. Mesmo com o 
fim do colonialismo político, relações coloniais ancoradas na hierarquia racial permaneceram. Aníbal Quijano (1992) denomina tal permanência como colonialidade do poder.

Mas a uniformização europeia não eliminou a diferença e a desigualdade racial. Entre Modernidade e Colonialidade há um espaço formado pelo encontro entre projetos globais e modernizadores (Modernidade) e a implementação desses projetos via exploração e expropriação (CoIonialidade). Esse espaço é denominado por Walter Mignolo (2003) de diferença colonial.

Movimentos de imposição sempre provocam movimentos de reações (por menores que sejam). Diferença colonial é o espaço onde as histórias locais, que estão inventando e implementando os projetos globais, encontram aquelas histórias locais que o recebem; é o lugar onde os projetos globais são forçados a se adaptar, integrar-se ou onde são adotados, rejeitados ou ignorados. A diferença Colonial para Mignolo, está na "/" entre Modernidade e Colonialidade (M/C). A criatividade e potencialidade são realidades incontestáveis no espaço da diferença colonial, qualidades em certa medida, encobertas pelos discursos dominantes empenhados em controlar o caos que lhe é próprio.

No entanto, o caos produz novas formas e contornos que, em fluxo constante aos já existentes, se juntam gerando possibilidades de criação. O espaço cultural da hibridez nega qualquer tentativa de absolutização, foge aos padrões convencionais e, por mais que a padronização seja a sua domesticação, é potencialmente criação.

No encontro em questão, antes do esboço de um novo universo religioso ser formado, diferentes noções de tempo/espaço e diversas visões de mundo se entrelaçam em um fluxo marcado pela constância e inconstância. Dá-se lugar à hibridez, ao híbrido e ao imprevisível e, novos signos e símbolos religiosos emergem fugindo ao padrão religioso imposto pelo cristianismo europeu.

O catolicismo, projeto moderno europeu, foi imposto na América. No entanto, entre essa corrente religiosa e religiosidades ameríndias criou-se um espaço da diferença onde emergiram religiosidades sincréticas e híbridas que mais tarde se misturaram a outras religiosidades, a exemplo das africanas. Os produtos, afro-brasileiros, santidades indí- 
genas, afro-indígenas, são vistos como misturas destituídas de originalidade e, classificadas como inferiores. Dessa forma, passam a existir à margem do cristianismo católico.

$\mathrm{Na}$ diferença colonial, a resistência pode ser construída questionando formas de poder como o machismo. A diferença colonial é o espaço onde é possível surgir mulheres fortes, autônomas, empoderadas. Capazes de construir mundos religiosos femininos onde a maternidade é marca fundamental e laço entre o passado e o presente.

No que se refere às mulheres nas religiões de matriz africana, maternidade espiritual é empoderamento e estimula visitas ao passado das comunidades tradicionais africanas, onde divindades femininas são arquétipos da autonomia e força da mulher no sacerdócio. Interpretações e aplicações dos saberes dos antepassados são expressas em rituais, cantigas, ritmos, performances corporais, gestos e palavras de mulheres líderes. Práticas que contrariam a visão machista do mundo ao mesmo tempo em que o interpela.

Nas atividades do terreiros afro-brasileiros, à frente dos rituais, as mulheres não são estáticas e não carregam a figura tradicional do feminino inibido à espera de soluções masculinas. São donas de conhecimentos antigos (africanos, indígenas, europeus). Saberes pré-coloniais que conseguem entrelaçar com conhecimentos da atualidade e aplicar na resolução dos problemas daqueles que as buscam. Promovem o diálogo entre culturas e se constituem como agentes da interculturalidade. G. é mamêto ${ }^{8}$ do Candomblé Angola e sacerdotisa de Umbanda. O terreiro onde atende também é sua casa de morada. Umbandista desde os 9 anos de idade, o ambiente do misticismo é parte e dimensão da sua vivência física, psíquica e espiritual. Respira o ar do misticismo desde que se entende "por gente". Sua avó realizava atendimentos espirituais e, à medida que G. se inseriu na Umbanda, tornou-se sua auxiliar, herdando sua atuação na umbanda.

A estrutura física dessa mameto reflete o respeito que possui no universo afro-sertanejo. Imponente, de uma beleza singular que somente Ingurucema ${ }^{9}$ tem: porte de rainha-guerreira. Autoritária, sua voz ecoa

Mãe no Candomblé Angola.

lansã na cultura iorubá. 
firme, forte e segura. Conhecida como dotada de grande conhecimento tanto da Umbanda/Quimbanda quanto do Candomblé, G. possui a personalidade daquela que carrega na cabeça. É ação e prática, desvenda mistérios sem grandes especulações. Nada deve ficar para depois. De raciocínio rápido, entende que o que deve ser feito deve ser em tempo hábil. Seu corpo e olhar são espelhos, identificam seu lugar no campo afro-sertanejo: Dona e Mameto.

Potentada espiritual, mãe de personalidade forte, observadora, acolhedora, justa e nada sutil. As palavras são ditas sem desperdício, diz o que tem a dizer, sem delongas, sem render assunto como ela mesma diz, pois a verdade não deve ser temida. Injustiça a incomoda e as guerras não são para serem perdidas. São demonstração de sua força e conhecimento, armas que utiliza como mãe de desvalidos e, como amiga e conselheira. Psicóloga afro-sertaneja. ${ }^{10}$ Desconfiada, observa o inimigo de seus filhos espirituais e, na hora certa, desfere o golpe: palavras e magia cortam rente impondo silêncios. Não perde batalhas! Vence guerras! Não conhece o fel da derrota. À frente do terreiro, é mãe-sacerdotisa de umbanda e mameto no Candomblé Angola, onde promove a interculturalidade entre Umbanda, Quimbanda e Candomblé.

A concepção de interculturalidade que comungamos neste texto é a desenvolvida por Catherine Walsh (2014), pensadora da descolonialidade. Para ela, a interculturalidade é impulso capaz de superar a matriz colonial do poder, pois organiza no espaço da diferença colonial políticas da subjetividade. Para essa pensadora, são necessárias políticas que estimulem a reconstrução de seres de formas de poder e de saber. Isso é possível no espaço da diferença colonial mediante políticas direcionadas à rearticulação de conhecimentos dos antepassados.

Nessa perspectiva, interculturalidade é projeto de afirmação e fortalecimento do que é próprio a um grupo mediante, acreditamos, o diálogo com os antepassados. Independentemente de ocorrer via estímulo de políticas públicas, como coloca Catherine Walsh, a reafir-

10 Termo que utilizamos para nos referir à religiosidade afro-brasileira no sertão norte mineiro, onde desenvolvemos pesquisas. Partimos do pressuposto que o sertão, por ser lugar de fronteira, é lugar propício para o erguimento de universos simbólicos fronteiriços como o campo religioso afro-sertanejo. 
mação do que é próprio a um grupo ocorre quando esse se conecta à sua ancestralidade, buscando conhecimentos dessa. Para isso, é necessária uma hermenêutica destituída da lógica da razão instrumental. Uma hermenêutica dada pela coerência religiosa que não desconecta ancestralidade do tempo atual. Que vislumbra o mundo como regido por forças que o especialista religioso deve compreender como funcionam.

Assim, percebemos a interculturalidade nas práticas da sacerdotisa G. O diálogo intercultural caracteriza o terreiro onde essa sacerdotisa desenvolve suas atividades. Interculturalidade denunciada pelo Assentamento de Tempo, ${ }^{11}$ pelo Assentamento da inquiciana ${ }^{12}$ Ingurucema, ${ }^{13}$ além do Pejí de Umbanda e do quarto de Exu com esses ceivados e assentados.

A interculturalidade também é evidenciada nos rituais que são promovidos. Os rituais públicos de UmbandaQuimbanda ocorrem em torno de imagens de santos católicos e imagens de guias de Umbanda como Preto Velho e Caboclo. Os privados, destinados aos clientes tanto na Umbanda/uimbanda quanto no Candomblé. Esse quadro místico e religioso constitui o terreiro de G., como um terreiro afro-sertanejo, ou seja, intercultural, à medida que conjuga elementos da Umbanda/Quimbanda e Candomblé Angola.

Diferentes visões de mundo, que vão além da Modernidade europeia, são conformadas sob a direção de uma mulher que em seu terreiro promove o diálogo entre tradições e culturas diferentes. Isso, sem ser pensado e racionalizado. É um processo intuitivo, de conexão com a ancestralidade. Que depende da perspicácia e do conhecimento dessa mãe de santo sobre as tradições religiosas africanas, indígenas e cristãs.

Ao acompanhar atendimentos dessa mãe de santo às pessoas que a procuram, ávidas de solução de problemas, tivemos a oportunidade de testemunhar como desempenha a interculturalidade. Para ela, a entidade exu, seja feminino ou masculino, desliza pelas três energias Umbanda/ Quimbanda/Candomblé. Está no jogo de cartas - exu Cigano - e no jogo de búzios - exu mensageiro -. É a ele que se fazem oferendas antes de "agradar" qualquer orixá, e é ele que resolve problemas humanos

Tempo ou Ktembo é considerado o patrono do Candomblé Angola sendo sua identidade.

Divindade na cultura banto.

13 lansã na cultura banto. 
desde disputas amorosas até profissionais.

Sobre os sacrifícios a Exu nas religiões de matriz africana, Admilson Eustáquio Prates (2010, p. 113) esclarece que "o sangue ritual é utilizado para conceder vida e transformar tristeza em alegria, a dor em prazer". Esse cientista da religião coloca o sangue como puro e responsável pela vida nas religiões de matriz africana. A visão afro-brasileira, portanto, contraria a cultura cristã, onde o martírio e sacrifício do Cristo são vistos como divinos. O sagrado afro-brasileiro, legado das religiosidades africanas e indígenas, atemoriza, causa indignação para a sociedade ocidental, que se percebe em tempo posterior à barbárie. Ainda, é um sagrado que se deixa em mãos femininas.

Percebe-se que $G$ tem uma forte intimidade com essa entidade a ponto de ser uma das sacerdotisas mais procuradas na região para resolver questões difíceis, sejam elas quais forem. Sua fama como conhecedora dessa entidade é grande. Ora, Exu está na Quimbanda, a outra face da Umbanda. Está no candomblé, está no mundo, acompanha seres humanos. Divindade ou entidade, exu é onipresente. Segundo Liana Trindade e Lúcia Coelho (2006, p. 23), para o africano, o universo é um campo de forças em movimento de equilíbrio e desequilíbrio, forças que são dirigidas por princípios dinâmicos e estruturantes, esses são simbolizados nas religiões africanas pela divindade Exu. Esse é princípio dinâmico, força vital que sustenta o universo e a existência humana, e como tal, é condutor à ancestralidade. É a aliança entre afro-brasileiros e seus antepassados.

A visão que trazemos neste texto, reiteramos, é uma visão marginal, via uma epistemologia marginal, como o pensamento descolonial capaz de articular marginais como a religiosidade afro-brasileira e muIheres sacerdotisas. Para Walter Mignolo (2014), a crítica descolonial desenvolvida é uma epistemologia dissonante das epistemes ocidentais que especulam sobre a vida sem contemplar subjetividades como o negro, o indígena e a mulher. Dessa forma, emitem visões limitadas e restritivas do poder.

Maria Lugones (2014a), feminista descolonial, nos diz que o gênero é uma das principais categorias dentro do sistema mundial moderno. Com esse, formas de exploração das mulheres, limitação de sua liberdade e de seu espaço foram legitimadas, criando abismos e desigualdades 
entre elas e os homens. A colonialidade para essa feminista, diz respeito à situação de inferiorização da mulher nas regiões que foram colonizadas, inferiorização que decidiu e transformou os corpos de mulheres em vítimas de violência colonial.

Sobre a subjugação dos povos americanos e africanos ao poder europeu, Aimé Césaire (2006) alerta para o embrutecimento do europeu que coisifica os povos explorados, os reduz à meros instrumentos, meios de enriquecimento. Quando direcionamos tal violência às mulheres na América Latina, compreendemos Maria Lugones (2014a, 2014b), quando essa nos apresenta a colonização como processo de redução e desumanização feminina, inclusive pelos sistemas religiosos.

Em relação a esse, não podemos esquecer a visão maniqueísta do bem e do mal que propagam. Visão que domina principalmente as religiões dos livros. $\mathrm{O}$ mal foi associado à figura feminina responsabilizada pela desobediência a Deus. A mulher, historicamente, tem sofrido toda sorte de repressão por tal visão que, conjugada ao Sistema Mundial Moderno, foi de extrema importância para o seu controle tanto pelo homem quanto pelo Estado. Entre outras situações de opressão, a mulher se encontra em marginalidade epistêmica.

O racismo e o patriarcalismo são as bases em que se estabeleceram no Sistema Mundial Moderno, lócus de enunciação e de controle do conhecimento. Sustentam-se na cosmologia cristã e em bases conceituais da ciência ocidental (tecnologia) e da filosofia, pois como afirma Walter Mignolo (2014, p. 45): "Se se controla o conhecimento se pode, então, construir e manter, através dos séculos, uma série de hierarquias que formam, conformam e mantêm a matriz colonial de poder". ${ }^{14}$

As hierarquias, nas relações de poder, manifestam a colonialidade. Sobre isso, Walter Mignolo (2014, p. 33) alerta para a hierarquia espiritual, onde os cristãos possuem mais valor do que a espiritualidade não cristã e, a hierarquia epistêmica onde o conhecimento ocidental, inclusive o teológico, é colocado como superior em relação às cosmovisões e conhecimentos religiosos não ocidentais, a exemplo das religiões de matriz africana.

14 "Si se controla el conocimiento se puede entonces construir y mantener, a través de los siglos una serie de jerarquias que forman, conforman y mantienen la matriz colonial de poder." 
Nas religiões afro-brasileiras, a mulher é detentora de conhecimentos, é agenciadora da fé quando se torna mãe de santo, líder religiosa. Subverte a colonialidade via patriarcado e o machismo ao transformar o espaço religioso em um espaço feminino, fazendo dele um lócus de enunciação.

Enfim, a tensão religião e gênero quando articulada a uma epistemologia marginal, neste texto o pensamento descolonial, ${ }^{15}$ desvela atores desautorizados pela episteme hegemônica ocidental como as mulheres sacerdotisas nas religiões de matriz africana. Mulheres que em conexão com a ancestralidade aplicam conhecimentos dos antepassados, articulando-os aos conhecimentos ocidentais, na assistência a pessoas que as procuram. Praticam a interculturalidade e a descolonização.

\section{REFERÊNCIAS}

CÉSAIRE, Aimé. Discurso sobre el colonialismo. Madrid: Ediciones Akal, 2006.

FORNET-BETANCOURT, Raul. Interculturalidade. Críticas, diálogo e perspectivas. São Leopoldo: Nova Harmonia, 2004.

FORNET-BETANCOURT, Raul. Religião e interculturalidade. São Leopoldo: Nova Harmonia, 2007.

FORNET-BETANCOURT, Raul. Supuestos filosóficos del diálogo intercultural, 2011. Disponível em: <http://them.polylog.org/1/ffr-es.htm. Acesso em 15/03/2011>. Acesso em: 24 out. 2018.

LUGONES, Maria. Rumo a um feminismo descolonial. In: Revista de Estudos Feministas, Florianópolis, 22 (3), set./dez. 2014a, p. 935-952.

LUGONES, María. Colonialidad y género. In: MIÑOSO, Yuderkys Espinosa; CORREAL, Diana Gómes; MUÑOZ, Karina Ochoa (editoras). Tejiendo de outro modo: Feminismo, epistemología y apuestas descolonialies em Abya Yala. Editorial Universidade del Cauca, 2014b. MIGNOLO, Walter. Desobediência epistêmica: Retórica de la modernidad, lógica de la colonialiadad y a gramática de la descolonialidad. Colleccion razón política.

Ediciones del signo. Primeira edição, Buenos Aires, 2010.

MIGNOLO, Walter. Histórias locais/projetos globais. Colonialidade, saberes subalternos e pensamento liminar. Trad. Solange Ribeiro de Oliveira. Belo Horizonte: Editora

15 Não restringimos apenas ao pensamento descolonial, pois epistemologias marginais como o pensamento abissal de Boaventura Santos, o pensamento intercultural de Raúl FornetBetancourt (2004, 2007, 2011) ou a double critique de Abdélkebir Katibi são igualmente epistemologias marginais. 
UFMG, 2003.

MIGNOLO, Walter. Una concepción descolonial del mundo: conversaciones de Francisco Carballo con Walter Mignolo. Buenos Aires: Ediciones del Signo: Buenos Aires, Coleçción El desprendimiento, Project (Duke University) 2014.

MIGNOLO, Walter; LINERA, Álvaro Garcia; WALSH, Catherine. Interculturalidad, descoIonización del Estado y del conocimiento. Ediciones del Signo: Buenos Aires, Coleçción El desprendimiento, Project (Duke University) 2014.

QUIJANO, Aníbal. Colonialidad y modernidade-racionalidad. In: BONÍLIA, Heraclio (Compilador). Los conquistados. 1492 y la población indígena de las Américas. Bogotá: Tercer Mundo Editores, 1992.

QUIJANO, Aníbal. Colonialidade do poder, eurocentrismo e América Latina. In: A colonialidade do saber, Eurocentrismo e ciências sociais. Perspectivas Latino-americanas. Buenos Aires: GLACSO, 2005.

TRINDADE, Liana; COELHO, Lúcia. Exu: o homem e o mito. Estudo de Antropologia Psicológica. São Paulo: Terceira Margem, 2006.

WALSH, Catherine. Colonialidad, conocimiento y diáspora afro-andina: construyendo etnoeducación e interculturalidad en la universidad. In: RESTREPO, E.; ROJAS, A. (Orgs.). Conflicto e (in) visibilidade: retos en los estúdios de la gente negra en Colombia. Popayán, Editorial Universidad del Cauca, 2004.

WALSH, Catherine. Interculturalidad y colonialidad del poder. Un pensamiento, y posicionamento otro desde la diferencia colonial. In: LINERA, MIGNOLO, WALSH. Interculturalidad, descolonización del Estado y del conocimiento. Nome da coleção: El desprendimiento. Buenos Aires: Edições Del Signo, 2014.

Submetido em: 2-11-2018

Aceito em: 29-11-2018 